\title{
Intrinsic molecular subtypes of breast cancers categorized as HER2-positive using an alternative chromosome 17 probe assay

Neelam V. Desai ${ }^{1{ }^{*}}$, Vanda Torous ${ }^{2+}$, Joel Parker ${ }^{3}$, James T. Auman ${ }^{4}$, Gary B. Rosson ${ }^{4}$, Cassandra Cruz ${ }^{1}$, Charles M. Perou ${ }^{3}$, Stuart J. Schnitt ${ }^{5}$ and Nadine Tung ${ }^{1}$

\begin{abstract}
The 2013 update of the American Society of Clinical Oncology-College of American Pathologists (ASCO-CAP) human epidermal growth factor receptor 2 (HER2) testing guidelines recommend using an alternative chromosome 17 probe assay to resolve HER2 results determined to be equivocal by immunohistochemistry (IHC) or fluorescence in-situ hybridization (FISH). However, it is unclear if cases considered HER2-positive $\left(\mathrm{HER}_{2}{ }^{+}\right.$) by the alternative probe method are similar to those classified as HER2 ${ }^{+}$by traditional IHC and FISH criteria and benefit the same from HER2-targeted therapies. We studied the clinical and pathologic features of all 31 breast cancers classified as HER2 ${ }^{+}$by the alternative probe method at our institution since 2013 and determined their PAM50 intrinsic molecular subtypes. For comparison, we analyzed 19 consecutive cases that were classified as HER2 ${ }^{+}$by traditional FISH criteria during the same time period. Thirty (97\%) cancers in the alternative probe cohort were estrogen receptor (ER)-positive $\left(E^{+}\right)$, while only $9 / 19(47 \%)$ of traditional HER2 controls were $\mathrm{ER}^{+}(p=0.0002)$. Sufficient tissue for intrinsic subtype analysis was available for 20/31 cancers in the alternative probe cohort and $9 / 19$ in the traditional HER2 ${ }^{+}$group. None (0\%) of the 20 alternative probe-positive cases were of the HER2-enriched intrinsic subtype, while 8/9 (89\%) of those HER2 ${ }^{+}$by traditional FISH criteria were HER2-enriched $(p=0.0001)$. These findings suggest that breast cancers classified as HER2 ${ }^{+}$only by the alternative probe method are biologically distinct from those classified as HER2 ${ }^{+}$by traditional criteria, and raises questions as to whether or not they derive the same benefit from HER2-targeted therapies.
\end{abstract}

Keywords: HER2-positive breast cancer, PAM50 intrinsic subtype, HER2 alternative probe, ASCO-CAP guidelines

Approximately $15 \%$ of breast cancers are classified as human epidermal growth factor receptor 2 (HER2)-positive $\left(\right.$ HER2 ${ }^{+}$) [1]. HER2 positivity confers an aggressive phenotype and was associated with poor long-term outcomes [2] until the incorporation of HER2-targeted agents into treatment which resulted in a $50 \%$ reduction in recurrence and a $30 \%$ improvement in survival $[3,4]$.

\footnotetext{
* Correspondence: ndesai@bidmc.harvard.edu

${ }^{\dagger}$ Neelam V. Desai and Vanda Torous contributed equally to this work.

'Department of Hematology-Oncology, Beth Israel Deaconess Medical Center and Harvard Medical School, 330 Brookline Ave, Shapiro 9, Boston, MA 02215, USA

Full list of author information is available at the end of the article
}

The two most common methods for HER2 testing are immunohistochemistry (IHC) to assess protein overexpression and fluorescence in-situ hybridization (FISH) to assess gene amplification. Single-probe FISH enumerates HER2 copies per nucleus. Dual-probe FISH includes both an HER2 probe and a chromosome 17 centromere probe, providing an HER2/CEP17 ratio in addition to absolute HER2 copy number [5]. Intrinsic molecular subtype analysis using gene expression profiling is not used clinically, but may better represent the inherent biologic heterogeneity of breast cancer than conventional biomarkers such as estrogen receptor (ER), progesterone receptor (PR), and HER2 [6, 7]. While all intrinsic

(c) The Author(s). 2018 Open Access This article is distributed under the terms of the Creative Commons Attribution 4.0 International License (http://creativecommons.org/licenses/by/4.0/), which permits unrestricted use, distribution, and 
molecular subtypes have been observed among clinically $\mathrm{HER}^{+}$breast cancers defined by traditional IHC/FISH criteria, the majority (67\%) are classified as HER2-enriched, with ER-positive $\left(\mathrm{ER}^{+}\right) / \mathrm{HER} 2^{+}$ cases being HER2-enriched $54 \%$ of the time [8]. In contrast, among clinically HER2-negative (HER2 ${ }^{-}$) cases, only $\sim 7 \%$ are of the HER2-enriched subtype [9]. Recent data suggest that the HER2-enriched molecular subtype may be a better predictor of response to HER2-targeted therapy than IHC or FISH assessments [10].

The American Society of Clinical Oncology (ASCO) and College of American Pathologists (CAP) updated their HER2 testing guidelines in 2013 [11]. It is now recommended that for HER2 equivocal cases (i.e., IHC $2+$ or HER 2 copies $\geq 4$ and $<6$ and HER2/CEP17 ratio $<2$ ), FISH be performed using a probe for other genes on chromosome 17 to serve as the denominator to determine the HER2/chromosome 17 ratio. Genes such as retinoic acid receptor alpha (RARA), Smith-Magenis Syndrome (SMS), or tumor protein p53 (TP53) are located further away from HER2 than the centromere and are thus less likely to be co-amplified with HER2 than the centromere. Thus, an HER2/alternative chromosome 17 probe ratio of $\geq$ 2 may more accurately reflect HER2 gene amplification than the HER2/CEP17 ratio [12].

Using the alternative probe method has resulted in an increased number of breast cancers classified as HER2-positive [13]. However, whether or not these cancers have similar clinical and pathologic features or respond as well to HER2-targeted therapy as breast cancers defined as HER2-positive by traditional IHC/FISH criteria is unclear.

We identified all breast cancers at our institution since 2013 classified as HER2-positive only by the alternative probe method. We identified 31 such cases, and 20 of those had sufficient tissue for PAM50 intrinsic subtype analysis. As a comparison group, we selected 19 consecutive cases classified as HER2 ${ }^{+}$by traditional FISH criteria during the same period. We reviewed their clinical and pathologic features and determined intrinsic molecular subtype analysis using the PAM50 research-based assay as previously described [14] (Tables 1 and 2).

Among the 31 , alternative probe-positive cases, 30 (97\%) were $\mathrm{ER}^{+}$and 11 (35\%) were high grade. In contrast, among the 19 cases that were HER2 ${ }^{+}$by traditional FISH criteria, nine $(47 \%)$ were $\mathrm{ER}^{+}$and $14(74 \%)$ were high grade $(p=0.0002)$. Repeat HER2 testing was performed on a second tumor sample in 11 cases and seven of those were negative for HER2 gene amplification by both traditional FISH criteria and alternative probe method. Two cases were confirmed HER2 $^{+}$by conventional FISH and two only by the alternative probe method (Tables 1 and 2).

Adequate tissue for PAM50 intrinsic subtype analysis was available for 20 alternative probe-positive cases and nine cases that were HER ${ }^{+}$by traditional FISH criteria. None $(0 \%)$ of the 20 alternative probe cancers had HER2-enriched intrinsic subtype, while eight $(89 \%)$ of the nine HER2 ${ }^{+}$traditional controls were of the HER2-enriched molecular subtype $(p=$ 0.0001).

Clinical and pathologic data for patients in the alternative probe-positive cohort is provided in Table 1. Staging information was available for 24 patients. Twenty-one had early-stage disease $(12=$ node negative, $9=$ node positive), one patient had a postmastectomy recurrence, and two patients had metastatic disease. Treatment information was available for 22 patients. Only four patients did not receive HER2-targeted therapy, one with metastatic disease and three with node-negative early-stage disease. Of the early stage patients who did receive HER2-targeted therapy, only two received it in the neoadjuvant setting, along with chemotherapy; one had a pathologic complete response (pCR) and one had partial responses (PR). Similarly, only four patients in the traditional HER2 ${ }^{+}$cohort received neoadjuvant HER2-targeted therapy with chemotherapy; two had a pathologic PR and two (both patients with HER2-enriched subtype) achieved pCR (Table 2). Given the small number of patients treated in the neoadjuvant setting, we cannot draw meaningful conclusions regarding response to HER2-targeted therapy among the alternative probe cases.

In the alternative probe-positive cohort, when considering the early-stage patients who received concurrent chemotherapy and HER2-targeted therapy, all except one had $\mathrm{ER}^{+}$tumors, eight had no nodal involvement, and five had only N1a or N1mic disease. Had these tumors been considered HER2-negative, all might have been candidates for genomic expression assays to determine the need for chemotherapy, yet only three were evaluated for such (Table 1). Oncotype Dx was performed on tumors from three patients, with recurrence scores of 29, 26, and 12. The patient with the recurrence score of 12 had T1cN0 $\mathrm{ER}^{+}$disease, was treated with endocrine therapy only without any chemotherapy or HER2-targeted therapy, and remains in remission at the last follow-up.

In conclusion, these findings highlight the unique pathologic and molecular characteristics of breast cancers classified as HER2 ${ }^{+}$only by an alternative probe method, and raise questions regarding the appropriate management of these cancers. More data regarding response of these breast cancers to HER2-targeted therapies is needed. 


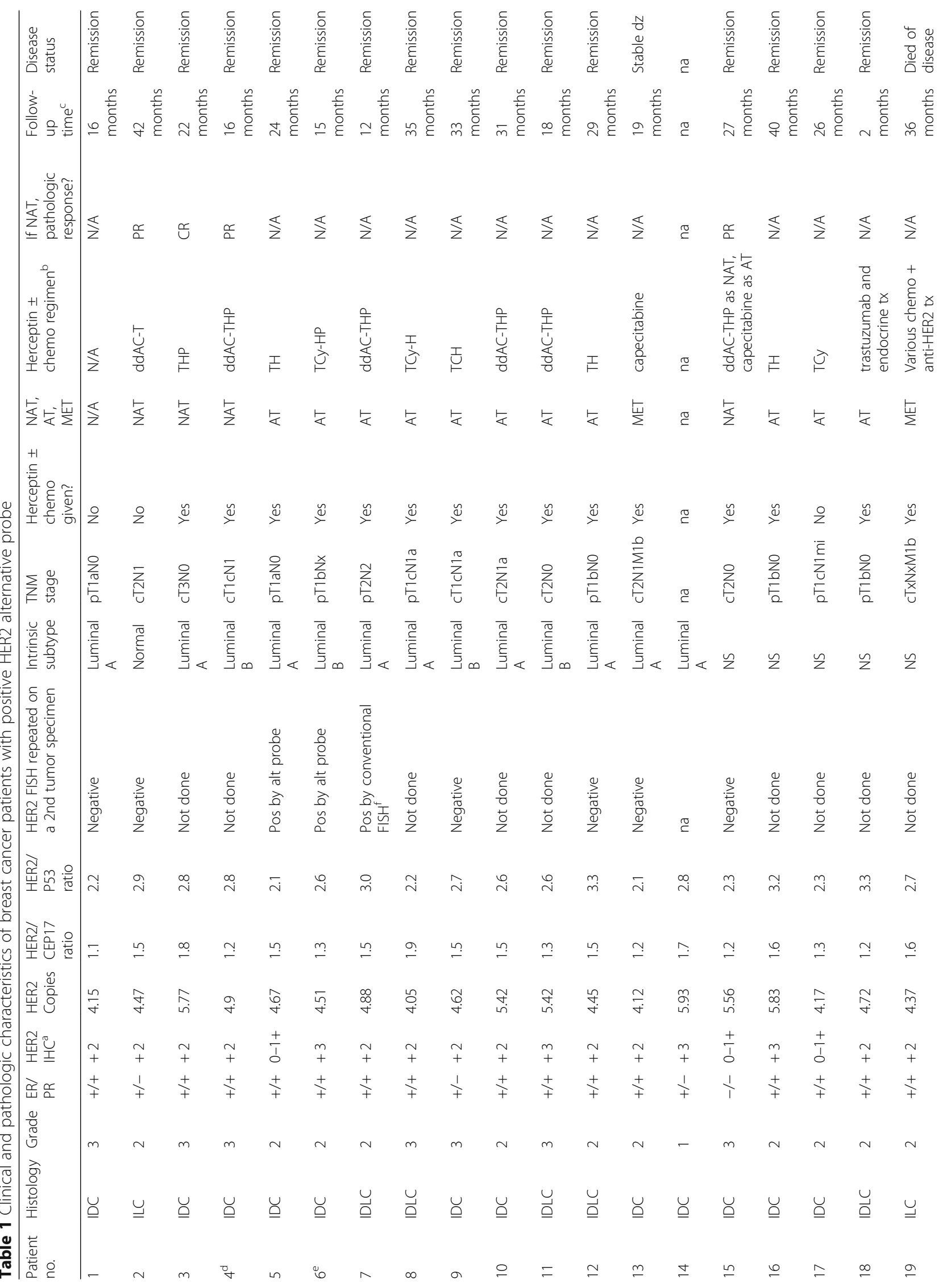




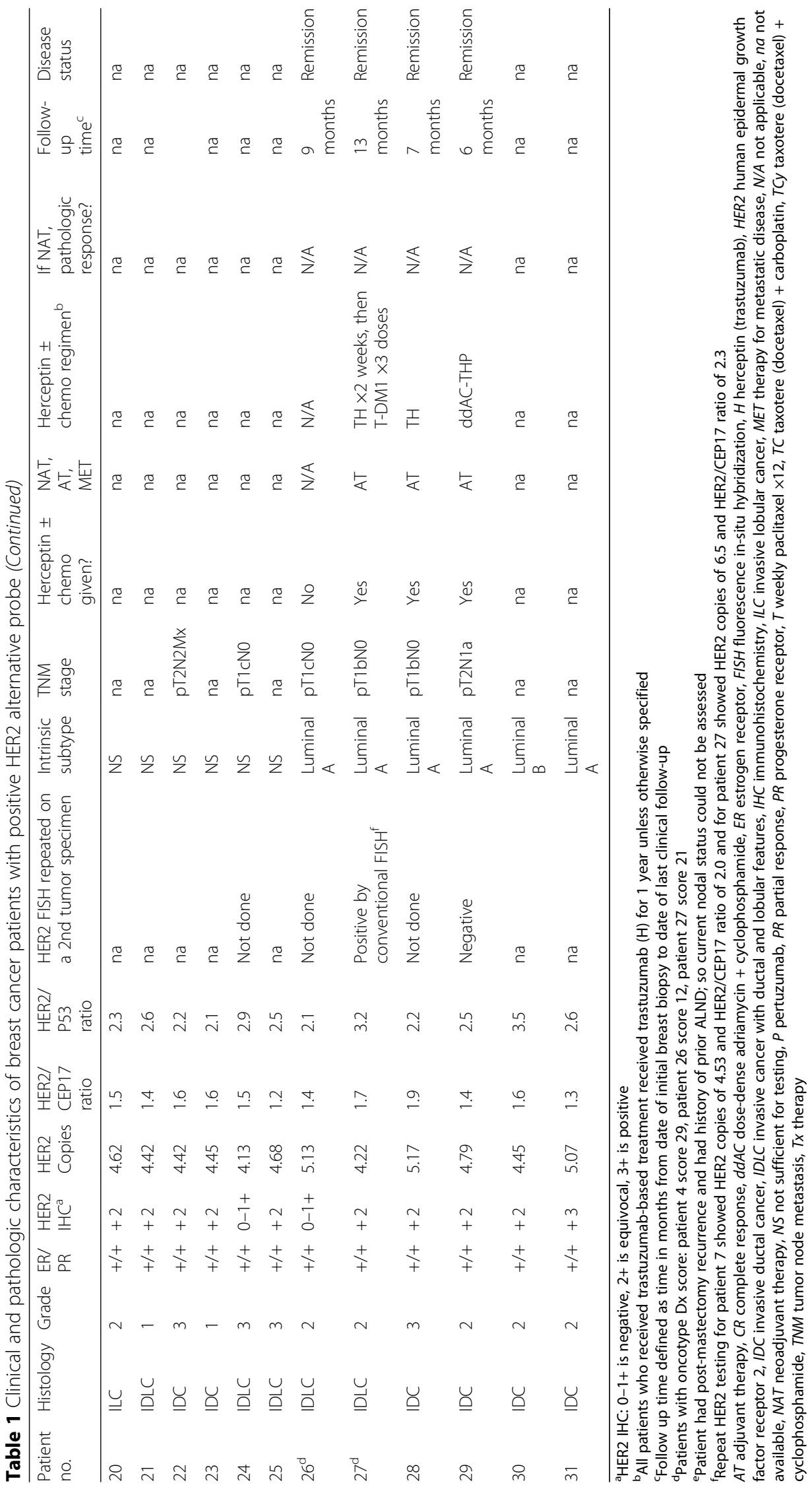


Table 2 Randomly selected consecutive HER2 ${ }^{+}$cases by traditional FISH criteria

\begin{tabular}{|c|c|c|c|c|c|c|c|c|c|c|c|c|c|c|}
\hline $\begin{array}{l}\text { Patient } \\
\text { no. }\end{array}$ & Histology & Grade & $\begin{array}{l}\text { ER/ } \\
P R\end{array}$ & $\begin{array}{l}\text { HER2 } \\
\text { IHC }\end{array}$ & $\begin{array}{l}\text { HER2 } \\
\text { copies }\end{array}$ & $\begin{array}{l}\text { HER2/ } \\
\text { CEP17 } \\
\text { ratio }\end{array}$ & $\begin{array}{l}\text { Intrinsic } \\
\text { subtype }\end{array}$ & $\begin{array}{l}\text { TNM } \\
\text { stage }\end{array}$ & $\begin{array}{l}\text { Herceptin } \pm \\
\text { chemo } \\
\text { given? }\end{array}$ & $\begin{array}{l}\text { NAT, } \\
\text { AT, } \\
\text { MET } \\
\end{array}$ & $\begin{array}{l}\text { Herceptin } \pm \\
\text { chemo } \\
\text { regimen }^{b}\end{array}$ & $\begin{array}{l}\text { If NAT, } \\
\text { pathologic } \\
\text { response? }\end{array}$ & $\begin{array}{l}\text { Follow- } \\
\text { up } \\
\text { time }\end{array}$ & $\begin{array}{l}\text { Disease } \\
\text { status }\end{array}$ \\
\hline 1 & IDC & 3 & $+/+$ & +3 & 19.1 & 5.8 & NS & pT1cNO & $\begin{array}{l}\text { No; patient } \\
\text { declined }\end{array}$ & N/A & N/A & $\mathrm{N} / \mathrm{A}$ & $\begin{array}{l}9 \\
\text { months }\end{array}$ & Remission \\
\hline 2 & IMPC & 2 & $-/-$ & +3 & 17.6 & 4.8 & NS & pT1bNx & $\begin{array}{l}\text { No; not } \\
\text { offered 2/2 } \\
\text { age/ } \\
\text { comorbidities }\end{array}$ & N/A & N/A & N/A & $\begin{array}{l}4 \\
\text { months }\end{array}$ & $\begin{array}{l}\text { Died of } \\
\text { AAA } \\
\text { rupture }\end{array}$ \\
\hline 3 & IDC & 3 & $+/+$ & +3 & 20.6 & 6.6 & $\begin{array}{l}\text { Luminal } \\
\text { A }\end{array}$ & cT2N1M0 & Yes & $\begin{array}{l}\text { NAT } \\
\& A T\end{array}$ & $\begin{array}{l}\text { NAT: T-DM1 } \\
+ \text { P on a trial, } \\
\text { AT: THP }\end{array}$ & $P R$ & $\begin{array}{l}25 \\
\text { months }\end{array}$ & Remission \\
\hline 4 & IDC & 3 & $+/+$ & +3 & $>10$ & 5.2 & HER2-E & CT1cNO & Yes & $\begin{array}{l}\text { NAT } \\
\& A T\end{array}$ & $\begin{array}{l}\text { NAT: T-DM1 } \\
+ \text { P on a trial, } \\
\text { then AT: do- } \\
\text { cetaxel } \times 4 \text { cy- } \\
\text { cles }+\mathrm{H} \\
\times 1 \text { year }\end{array}$ & $C R$ & $\begin{array}{l}12 \\
\text { months }\end{array}$ & Remission \\
\hline 5 & IDC & 3 & $-/-$ & +3 & $>20$ & $1.0^{\mathrm{d}}$ & HER2-E & CT1CNO & Yes & NAT & THP & $C R$ & $\begin{array}{l}18 \\
\text { months }\end{array}$ & Remission \\
\hline 6 & IDC & 2 & $-/-$ & +3 & 12.8 & 5.4 & NS & CT2-3 N1 & Yes & NAT & THP-ddAC & $P R$ & $\begin{array}{l}5 \\
\text { months }\end{array}$ & Remission \\
\hline 7 & IDC & 3 & $-1-$ & +3 & 23.3 & 5.3 & HER2-E & $\mathrm{CT} 2 \mathrm{NO}$ & na & na & $\mathrm{Na}$ & na & na & na \\
\hline 8 & IDC & 3 & $-1-$ & +3 & 20.7 & 6.4 & NS & $\mathrm{pT} 1 \mathrm{cNx}$ & Yes & AT & $\mathrm{TH}$ & N/A & $\begin{array}{l}27 \\
\text { months }\end{array}$ & Remission \\
\hline 9 & ILC & 2 & $-/-$ & +3 & $>6$ & 5.6 & NS & pT1ano & Yes & AT & $\mathrm{TH}$ & N/A & $\begin{array}{l}25 \\
\text { months }\end{array}$ & Remission \\
\hline 10 & IDC & 3 & $-/-$ & +3 & 26.3 & 7.6 & HER2-E & pT1bNo & Yes & AT & $\mathrm{TH}$ & N/A & $\begin{array}{l}30 \\
\text { months }\end{array}$ & Remission \\
\hline 11 & IDC & 3 & $-/-$ & +3 & $>10$ & $>3.8$ & HER2-E & pT1bNo & Yes & AT & $\mathrm{TH}$ & N/A & $\begin{array}{l}21 \\
\text { months }\end{array}$ & Remission \\
\hline 12 & IMPC & 3 & $-1-$ & +3 & 19.85 & 7.4 & HER2-E & pT1cN1a & Yes & AT & $\mathrm{ddAC-TH}$ & N/A & $\begin{array}{l}28 \\
\text { months }\end{array}$ & Remission \\
\hline 13 & IDC & 2 & $+/-$ & +3 & 37.2 & 6.8 & NS & pT1bNo & Yes & AT & $\mathrm{ddAC-TH}$ & N/A & $\begin{array}{l}26 \\
\text { months }\end{array}$ & Remission \\
\hline 14 & IDC & 3 & $+/-$ & +3 & 6.88 & 3.2 & NS & pT2N1a & Yes & AT & $\begin{array}{l}\text { THP } \\
\times 12 \text { weeks, } \\
\text { ddACX2 } \\
\text { (stopped } 2 / 2 \\
\text { SAE, } 1 \text { year } \\
\text { H) }\end{array}$ & N/A & $\begin{array}{l}22 \\
\text { months }\end{array}$ & Remission \\
\hline 15 & IDC & 3 & $+/-$ & +3 & $>20$ & 9.5 & NS & pT1aNo & Yes & AT & $\begin{array}{l}\text { T-DM1 on a } \\
\text { trial }\end{array}$ & $\mathrm{N} / \mathrm{A}$ & $\begin{array}{l}20 \\
\text { months }\end{array}$ & Remission \\
\hline 16 & IDC & 3 & $+/-$ & +3 & 23 & 8.1 & HER2-E & pT1bN1a & Yes & AT & ddAC-THP & N/A & $\begin{array}{l}17 \\
\text { months }\end{array}$ & Remission \\
\hline 17 & IDC & 3 & $+/+$ & +3 & $>10$ & 3 & NS & T2N1M1b & Yes & MET & $\begin{array}{l}\text { THP, AC, } \\
\text { various }\end{array}$ & N/A & $\begin{array}{l}35 \\
\text { months }\end{array}$ & $\begin{array}{l}\text { Alive, on } \\
\text { tx }\end{array}$ \\
\hline 18 & IDC & 3 & $-/-$ & +3 & 26.7 & 9.4 & HER2-E & na & na & na & na & na & na & na \\
\hline 19 & IDC & 2 & $+/-$ & +3 & 20.3 & 3.4 & NS & CT3N1 & na & na & na & na & na & na \\
\hline
\end{tabular}

${ }^{\mathrm{a} H E R 2}$ IHC: $0-1+$ is negative, $2+$ is equivocal, $3+$ is positive

${ }^{\mathrm{b}}$ All patients who received trastuzumab-based treatment received trastuzumab $(\mathrm{H})$ for 1 year unless otherwise specified

${ }^{C}$ Follow up time defined as time in months from date of initial breast biopsy to date of last clinical follow-up

d HER2 ratio 1.0 because HER2 copies and CEP 17 copies both $>20$, so HER2 alternative probe ratio performed to confirm HER2 status $A C$ Adriamycin + cyclophosphamide, $A T$ adjuvant therapy, $C R$ complete response, $d d A C$ dose-dense adriamycin + cyclophosphamide, $E R$ estrogen receptor, FISH fluorescence in-situ hybridization, $H$ herceptin (trastuzumab), HER2 human epidermal growth factor receptor 2, HER2-E HER2-enriched, IDC invasive ductal cancer, IHC immunohistochemistry, ILC invasive lobular cancer, IMPC invasive micropapillary cancer, MET therapy for metastatic disease, N/A not applicable, na not available, NAT neoadjuvant therapy, NS not sufficient for testing, $P$ pertuzumab, $P R$ partial response, $P R$ progesterone receptor, $T$ weekly paclitaxel $\times 12, T$-DM1 ado-trastuzumab, $T N M$ tumor node metastasis, $T x$ therapy 


\section{Funding}

Intrinsic subtype analysis was performed by CMP through the $\mathrm{NCl}$ Breast SPORE program (P50-CA58223), and by the Susan G. Komen (SAC-160074).

\section{Availability of data and materials}

All data generated and/or analyzed during this study are included in this published article.

\section{Authors' contributions}

NVD contributed to the initial concept, protocol writing, IRB submission, data collection and interpretation, and manuscript writing. VT contributed to protocol writing, IRB submission, tissue acquisition, and submission and manuscript review. CC helped with protocol writing, submission to IRB, and data collection. JP, JTA, and GBR contributed to tissue processing and interpretation for intrinsic subtype analysis, and manuscript review. SJS contributed to the initial concept, protocol writing, IRB submission, tissue acquisition, and submission and manuscript review. CMP contributed to the concept, tissue processing and interpretation of intrinsic subtype analysis. NT contributed to the initial concept, protocol writing, IRB submission, interpretation of data, and manuscript review. All authors read and approved the final manuscript.

\section{Ethics approval and consent to participate}

This study was approved by the Dana-Farber/Harvard Cancer Center IRB. The IRB protocol number is DFCl Protocol No. 17-054.

\section{Consent for publication}

Not applicable.

\section{Competing interests}

CMP is an equity stock holder, consultant, and Board of Director Member of BioClassifier LLC. CMP is also listed as an inventor on patent applications on the Breast PAM50 Subtyping assay. The remaining authors declare that they have no competing interests.

\section{Publisher's Note}

Springer Nature remains neutral with regard to jurisdictional claims in published maps and institutional affiliations.

\section{Author details}

${ }^{1}$ Department of Hematology-Oncology, Beth Israel Deaconess Medical Center and Harvard Medical School, 330 Brookline Ave, Shapiro 9, Boston, MA 02215, USA. ²Department of Pathology, Beth Israel Deaconess Medical Center and Harvard Medical School, Boston, MA, USA. ${ }^{3}$ Department of Genetics and Lineberger Comprehensive Cancer Center, University of North Carolina at Chapel Hill, Chapel Hill, North Carolina, USA. ${ }^{4}$ Department of Pathology and Laboratory Medicine and Lineberger Comprehensive Cancer Center, University of North Carolina at Chapel Hill, Chapel Hill, North Carolina, USA. ${ }^{5}$ Department of Pathology, Dana-Farber/Brigham and Women's Cancer Center and Harvard Medical School, Boston, MA, USA.

\section{Published online: 11 July 2018}

\section{References}

1. Figueroa-Magalhães MC, Jelovac D, Connolly R, et al. Treatment of HER2positive breast cancer. Breast. 2014;23(2):128-36.

2. Slamon DJ, Clark GM, Wong SG, et al. Human breast cancer: correlation of relapse and survival with amplification of the HER-2/neu oncogene. Science. 1987;235(4785):177-82

3. Romond EH, Perez EA, Bryant J, et al. Trastuzumab plus adjuvant chemotherapy for operable HER2-positive breast cancer. N Engl J Med. 2005;353(16):1673-84.

4. Perez EA, Romond EH, Suman VJ, et al. Trastuzumab plus adjuvant chemotherapy for human epidermal growth factor receptor 2-positive breast cancer: planned joint analysis of overall survival from NSABP B-31 and NCCTG N9831. J Clin Oncol. 2014;32(33):3744-52.

5. OA1 P, Guzman R, Cervantes M, Santiago A, Press MF. Characterization of HER2 status by fluorescence in situ hybridization (FISH) and immunohistochemistry (IHC). Methods Mol Biol. 1180(chapter 10):181-207.
6. Prat A, Bianchini G, Thomas M, et al. Research-based PAM50 subtype predictor identifies higher responses and improved survival outcomes in HER2-positive breast cancer in the NOAH study. Clin Cancer Res. 2014;20:511e21.

7. Gnant M, Sestak I, Filipits M, et al. Identifying clinically relevant prognostic subgroups of postmenopausal women with node-positive hormone receptor-positive early-stage breast cancer treated with endocrine therapy: a combined analysis of ABCSG-8 and ATAC using the PAM50 risk of recurrence score and intrinsic subtype. Ann Oncol. 2015;26(8):1685-9.

8. Cheang M, Martin M, Nielsn TO, et al. Defining breast cancer intrinsic subtypes by quantitative receptor expression. Oncologist. 2015;20:474-82.

9. Prat A, Carey L, Adamo B, et al. Molecular features and survival outcomes of the intrinsic subtypes within Her2-positive breast cancer. J Natl Cancer Inst. 2014;106(8). PMID 25139534

10. Llombart-Cussac A, Cortes J, Pare L, et al. HER2-enriched subtype as a predictor of pathological complete response following trastuzumab and lapatinib without chemotherapy in early-stage HER2-positive breast cancer (PAMELA): an open-label, single-group, multicentre, phase 2 trial. Lancet Oncol. 2017;18(4):545-54. PMID: 28238593

11. Wolff AC, Hammond MEH, Hicks DG, et al. Recommendations for human epidermal growth factor receptor 2 testing in breast cancer: American Society of Clinical Oncology/College of American Pathologists Clinical Practice guideline update. J Clin Oncol. 2013;31:3997-4013.

12. Tse $\mathrm{CH}$, Hwang HC, Goldstein LC, et al. Determining true HER2 gene status in breast cancers with polysomy by using alternative chromosome 17 reference genes: implications for anti-HER2-targeted therapy. J Clin Oncol. 2011;29(31):4168-74.

13. Shah MV, Wiktor AE, Meyer RG, et al. Change in pattern of HER2 fluorescent in situ hybridization (FISH) results in breast cancers submitted for FISH testing: experience of a reference laboratory using US Food and Drug Administration criteria and American Society of Clinical Oncology and College of American Pathologists guidelines. J Clin Oncol. 2016;34(29):3502-10.

14. Parker JS, Mullins M, Cheang MCU, Leung S, Voduc D, Vickery T, et al. Supervised risk predictor of breast cancer based on intrinsic subtypes. J Clin Oncol. 2009;27:1160-7. 